\title{
The Three-folded Skewness Test, when a Sample Size is Small
}

\author{
Piotr Sulewski \\ The Pomeranian Academy, ul. Arciszewskiego 22, 76-200 Stupsk, Poland \\ e-mail: informpiotr@interia.eu \\ (Received: 5 February 2009; revised: 16 July 2009; accepted: 16 July 2009; published online: 1 September 2009)

\begin{abstract}
The aim of this publication is to present a new goodness-of-fit test oriented toward normal distribution. The test uses three different versions of skewness measures: classic, median and Bowley's skewness. Critical values for these skewness measures at significance level $\alpha$ were determined. The power of the proposed test obtained on the basis of a numerical experiment was compared with the power of the Kolmogorov-Smirnov goodness-of-fit test (K-S test).
\end{abstract}

Key words: skewness test, empirical skewness, power test function, Visual Basic for Applications

\section{INTRODUCTION}

Statistical literature gives four different definitions of the skewness. Besides a very popular classic skewness, also Pearson's, median, and Bowley's skewnesses occur sporadically. In paper [6] the ability of these skewness measures toexpress asymmetry was compared, and the accuracy of their estimation from normal distribution was assessed. Testing for normality on the base classic skewness was presented in [5].

The presented article is intended to test for normality on the basis of the three-folded skewness test (TFS test). Classic, median, and Bowley's skewnesses are jointly employed to test whether a particular distribution comes from the normal population. In other words, the null hypothesis says that the actual distribution is a Normal one.

Execution of this type of investigations is possible by means of a computer in relation with a large number of calculations. A very popular Excel spreadsheet was chosen to develop the experimental environment. All calculations were performed by means of Visual Basic for Applications (VBA) procedures [7].

For the null hypothesis to be accepted, each of skewness estimates have to lie within its corresponding critical interval. These critical values were determined at significance level $\alpha \in\{0.01 ; 0.05 ; 0.1\}$, and for a sample size $n \in\{5,10,15,20,25,30\}$.

Next, the power of the TFS test was calculated. The power test (PT) function shows how probability of reject- ing the null hypothesis increases accordingly to the untruthfulness of the hypothesis. A role of untruth distribution is given to the lognormal distribution. Obtained results were compared with power of the K-S test.

\section{THE LOGNORMAL DISTRIBUTION}

The lognormal distribution belongs to distributions derived from the Normal distribution. The density function is given by [3]

$$
f(x)=\frac{1}{s \cdot x \cdot \sqrt{2 \pi}} \cdot \exp \left[-\frac{1}{2} \cdot\left(\frac{\ln (x)-m}{s}\right)^{2}\right](x>0)
$$

and cumulative distribution function

$$
F(x)=\Phi\left[\frac{\ln (x)-m}{s}\right],
$$

where $\Phi($.$) is a normal cumulative distribution function.$ Formal similarity (1) to the density function of normal distribution is large; however, parameters $m, s$ should not be interpreted as scale parameter and shape parameter.

The classic skewness of lognormal distribution takes a form

$$
\gamma_{K}=\exp \left(s^{2}+1\right) \cdot \sqrt{\exp \left(s^{2}-1\right)}
$$


The density function of lognormal distribution for combinations of parameter values presented in table 1 was exemplified in Fig. 1. Calculations were performed by means of user function LogNormal, which was created in VBA

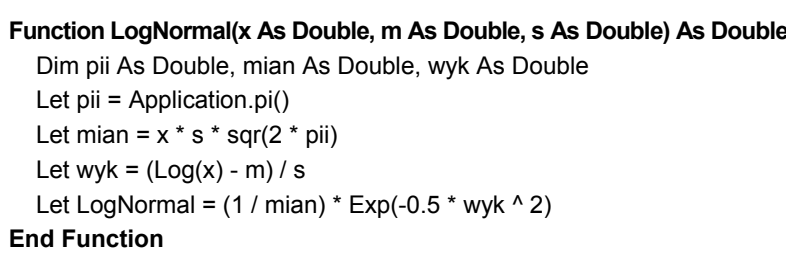

Table 1. Combinations of parameter values and values of the classic skewness

\begin{tabular}{c|c|c|c}
\hline Combination & $m$ & $s$ & $\gamma_{K}$ \\
\hline I & 0 & 0.641 & 2.5 \\
II & 0 & 0.920 & 5 \\
III & 0 & 1.165 & 10 \\
IV & 0 & 1.289 & 15 \\
V & 0 & 1.369 & 20 \\
\hline
\end{tabular}

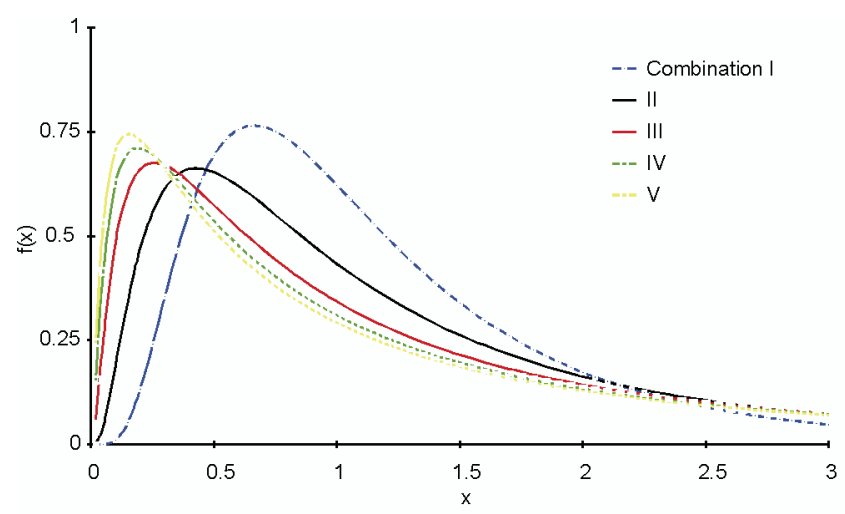

Fig. 1. Density function of lognormal distribution for combinations of parameter values presented in Table 1

For simulations to be performed, the use of random numbers is necessary. The generator of lognormal random numbers (function LogNormLos) arose from the generator of normal random numbers (function NormLos).

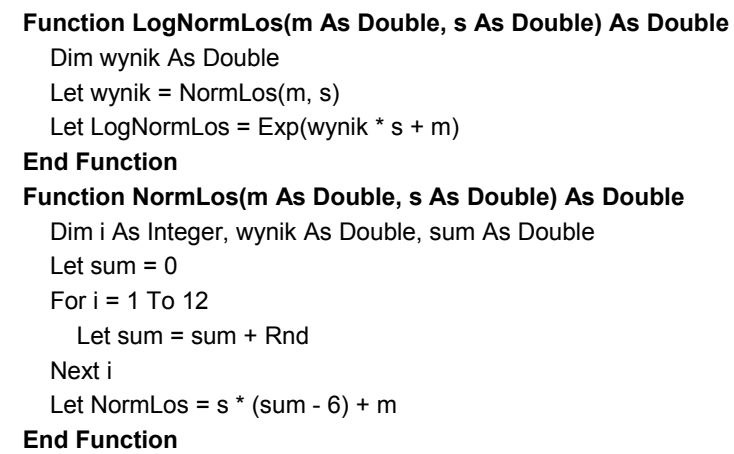

\section{THE EMPIRICAL CLASSIC SKEWNESS}

The empirical classic skewness is calculated as [1]

$$
\gamma_{C}^{*}=\frac{n \cdot \sqrt{n-1}}{n-2} \cdot \frac{\sum_{i=1}^{n}\left(x_{i}^{*}-\hat{\alpha}_{1}\right)^{3}}{\left[\sum_{i=1}^{n}\left(x_{i}^{*}-\hat{\alpha}_{1}\right)^{2}\right]^{3 / 2}},
$$

where $x_{i}^{*}(i=\overline{1, n})$ are values of the random variable lognormal distributed as well as $\hat{\alpha}_{1}$ is a sample mean value

$$
\hat{\alpha}_{1}=\frac{1}{n} \cdot \sum_{i=1}^{n} x_{i}^{*}
$$

The computer implementation of estimation of the classic skewness written in VBA was presented below. Comments were placed after apostrophes.

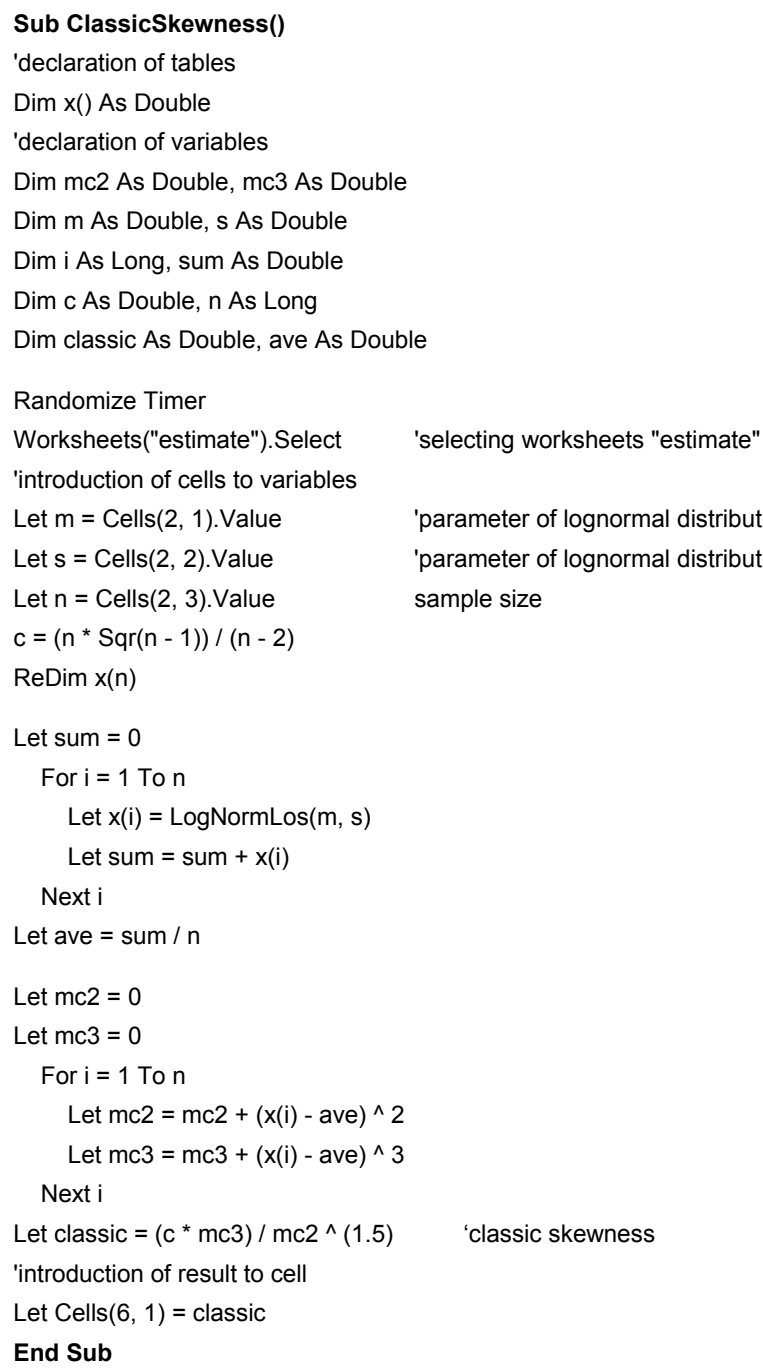




\section{THE EMPIRICAL MEDIAN SKEWNESS}

The empirical median skewness is given by [6]

$$
\gamma_{M}^{*}=\frac{\sqrt{n-1} \cdot\left(\hat{\alpha}_{1}-x_{0.5}^{*}\right)}{\sqrt{\sum_{i=1}^{n}\left(x_{i}^{*}-\hat{\alpha}_{1}\right)^{2}}}
$$

where $x_{0.5}^{*}$ is a sample median. Unknown values of quantiles of $k$-th order were replaced by appropriate order statistics [2]

$$
\text { number }=\operatorname{int}[n * k]+1
$$

The computer implementation of estimation of the median skewness written in VBA was presented below.

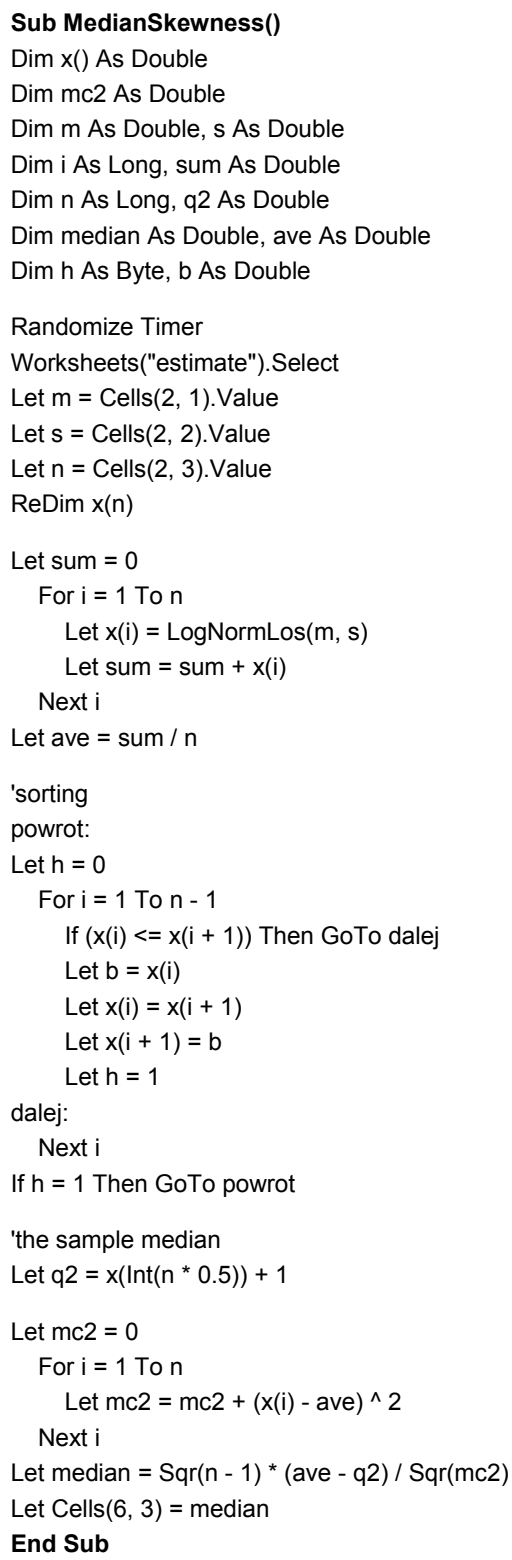

'median skewness

\section{THE EMPIRICAL BOWLEY'S SKEWNESS}

The empirical Bowley's skewness is defined as [4]

$$
\gamma_{B}^{*}=\frac{\left(x_{0.75}^{*}-x_{0.5}^{*}\right)-\left(x_{0.5}^{*}-x_{0.25}^{*}\right)}{\left(x_{0.75}^{*}-x_{0.25}^{*}\right)},
$$

where $x_{k}^{*}(0<k<1)$ are sample quantiles of the $\mathrm{k}$-th order.

The computer implementation of estimation of the Bowley's skewness written in VBA was presented below.

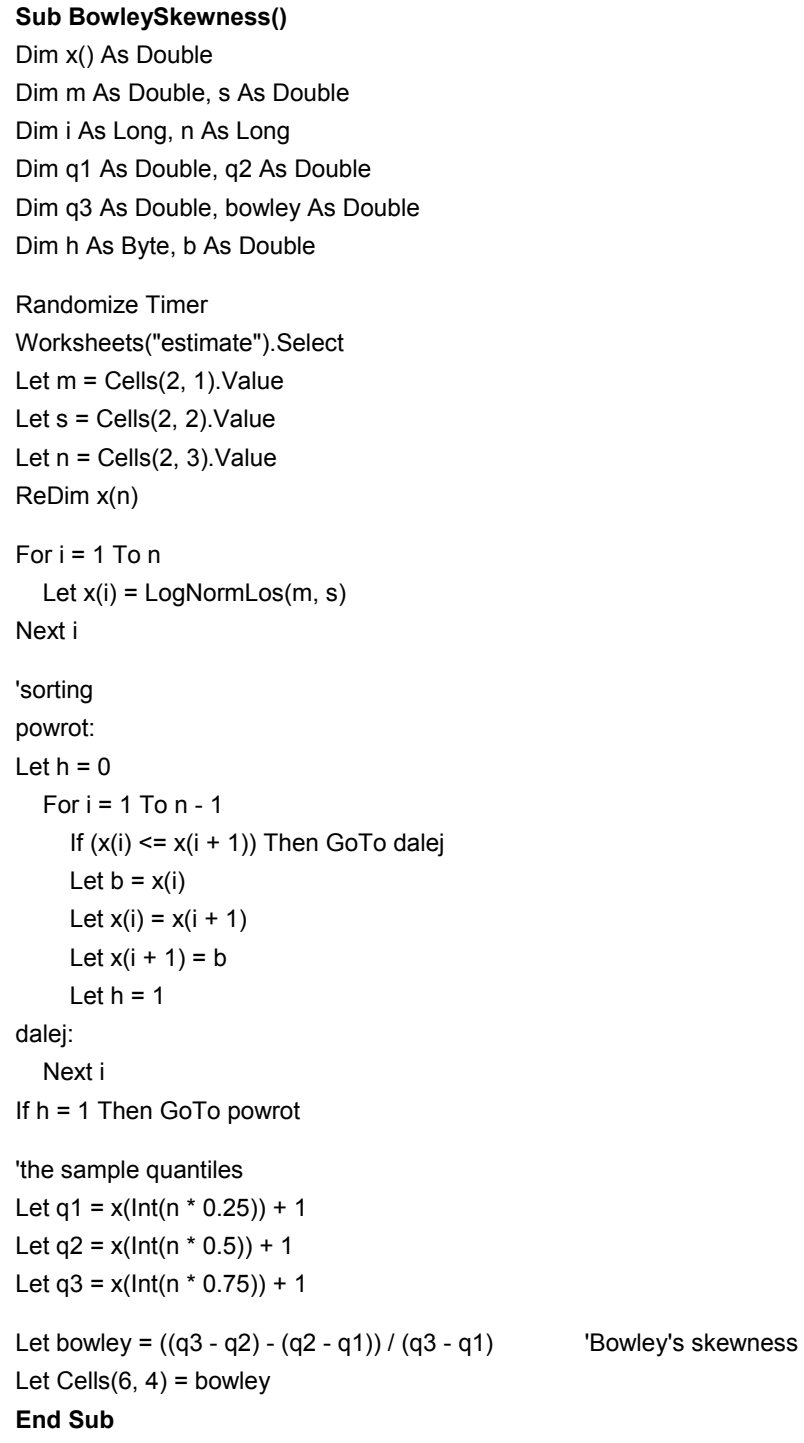

\section{THE GOODNESS-OF-FIT TEST APPLICABLE TO THE NORMAL DISTRIBUTION}

In this paper, three skewness measures described in the previous sections are jointly employed to test whether a particular distribution comes from the Normal population. 
In other words, the null hypothesis says that the actual distribution is a Normal one.

The essence of this joint employment is as follows. Three measures of skewness are estimated from the sample subjected to test. For the null hypothesis to be accepted, each of the skewness estimates have to lie within its corresponding critical interval $\left(X_{i}, X_{j}\right)$.

The first Monte-Carlo study on which this paper is based was intended to determine these critical values. The study consisted in generating samples coming from the Normal distribution. Such a great number of samples as 10240 enabled precise determination of critical values $X_{i}$ and $X_{j}$ at significance level $\alpha$ according to the following formulas [2]

$$
\begin{gathered}
i=\operatorname{int}\left[10240 \cdot \frac{\beta}{2}\right]+1, \\
j=\operatorname{int}\left[10240 \cdot\left(1-\frac{\beta}{2}\right)\right]+1,
\end{gathered}
$$

where $\beta=1-(1-\alpha)^{1 / 3}$. Obtained results at significance level $\alpha$ are presented in Tables 2-4.

Table 2. Critical values at significance level $\alpha=0.01$

\begin{tabular}{c|cc|cc|cc}
\hline $\begin{array}{c}\text { Simple } \\
\text { size }\end{array}$ & \multicolumn{2}{|c|}{$\begin{array}{c}\text { Classic } \\
\text { skewness }\end{array}$} & \multicolumn{2}{c|}{$\begin{array}{c}\text { Median } \\
\text { skewness }\end{array}$} & \multicolumn{2}{c}{$\begin{array}{c}\text { Bowley's } \\
\text { skewness }\end{array}$} \\
\hline$n$ & $X_{i}$ & $X_{j}$ & $X_{i}$ & $X_{j}$ & $X_{i}$ & $X_{j}$ \\
\hline 5 & -2.219 & 2.120 & -0.646 & 0.710 & -0.997 & 0.999 \\
\hline 10 & -2.134 & 2.010 & -0.727 & 0.477 & -0.967 & 0.803 \\
\hline 15 & -1.886 & 1.704 & -0.570 & 0.470 & -0.880 & 0.808 \\
\hline 20 & -1.728 & 1.482 & -0.530 & 0.362 & -0.729 & 0.734 \\
\hline 25 & -1.414 & 1.376 & -0.408 & 0.438 & -0.704 & 0.673 \\
\hline 30 & -1.497 & 1.374 & -0.399 & 0.385 & -0.664 & 0.595 \\
\hline
\end{tabular}

\begin{tabular}{|c|c|c|c|c|c|c|}
\hline \multirow{2}{*}{$\begin{array}{c}\text { Simple } \\
\text { size } \\
n \\
\end{array}$} & \multicolumn{2}{|c|}{$\begin{array}{c}\text { Classic } \\
\text { skewness }\end{array}$} & \multicolumn{2}{|c|}{$\begin{array}{c}\text { Median } \\
\text { skewness }\end{array}$} & \multicolumn{2}{|c|}{$\begin{array}{l}\text { Bowley's } \\
\text { skewness }\end{array}$} \\
\hline & $X_{i}$ & $X_{j}$ & $X_{i}$ & $X_{j}$ & $X_{i}$ & $X_{j}$ \\
\hline 5 & -2.026 & 2.018 & -0.611 & 0.609 & -0.984 & 0.980 \\
\hline 10 & -1.687 & 1.657 & -0.625 & 0.395 & -0.909 & 0.707 \\
\hline 15 & -1.405 & 1.448 & -0.435 & 0.425 & -0.725 & 0706 \\
\hline 20 & -1.2 & 1.2 & -0.4 & 0.323 & -0.651 & 0.667 \\
\hline 25 & -1.084 & & -0.344 & 0.341 & -0.606 & 0.589 \\
\hline 30 & -0.986 & 1.012 & -0.360 & 0.281 & -0.597 & 0.509 \\
\hline
\end{tabular}

Table 3. Critical values at significance level $\alpha=0.05$
Table 4. Critical values at significance level $\alpha=0.1$

\begin{tabular}{c|cc|cc|cc}
\hline $\begin{array}{c}\text { Simple } \\
\text { size }\end{array}$ & \multicolumn{2}{|c|}{$\begin{array}{c}\text { Classic } \\
\text { skewness }\end{array}$} & \multicolumn{2}{c|}{$\begin{array}{c}\text { Median } \\
\text { skewness }\end{array}$} & \multicolumn{2}{c}{$\begin{array}{c}\text { Bowley's } \\
\text { skewness }\end{array}$} \\
\hline $\mathrm{n}$ & $X_{i}$ & $X_{i}$ & $X_{i}$ & $X_{i}$ & $X_{i}$ & $X_{i}$ \\
\hline 5 & -1.822 & 1.843 & -0.561 & 0.579 & -0.959 & 0.974 \\
\hline 10 & -1.564 & 1.593 & -0.586 & 0.356 & -0.888 & 0.672 \\
\hline 15 & -1.186 & 1.326 & -0.385 & 0.385 & -0.669 & 0.630 \\
20 & -1.002 & 1.125 & -0.389 & 0.271 & -0.553 & 0.623 \\
\hline 25 & -0.956 & 0.971 & -0.302 & 0.329 & -0.546 & 0.544 \\
\hline 30 & -0.870 & 0.933 & -0.309 & 0.228 & -0.545 & 0.409 \\
\hline
\end{tabular}

Having critical values, one can start performing the second Monte-Carlo study intended to determine the power of the test. A substance PT function can be verbally expressed by saying that it is the function which shows how the probability of rejecting the null hypothesis increases accordingly to the untruthfulness of the hypothesis. A role of untruth distribution is given to the lognormal distribution. The computer procedure of the TFS test written in VBA was introduced below.

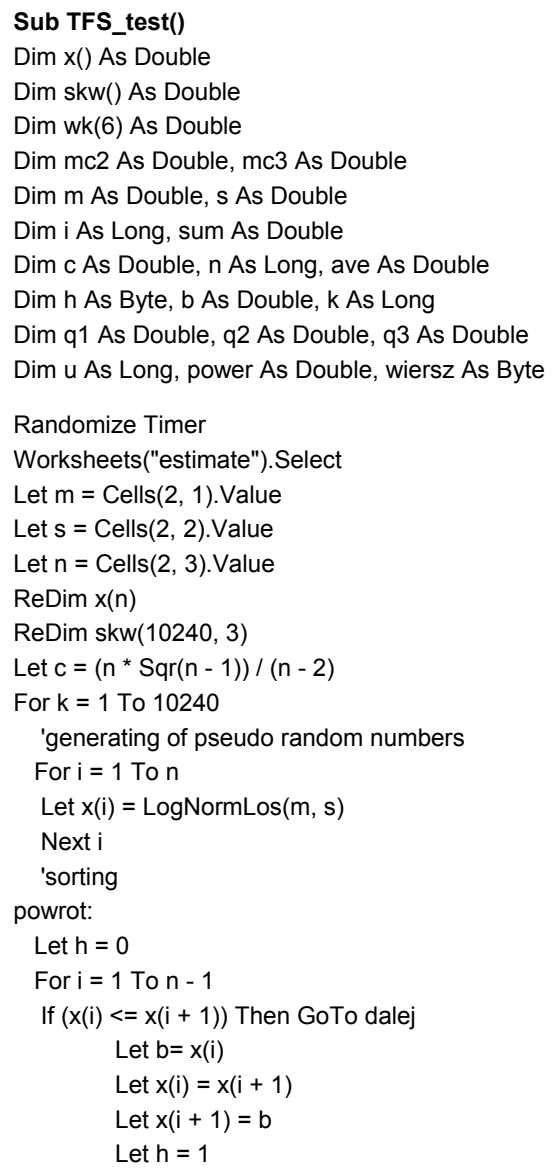




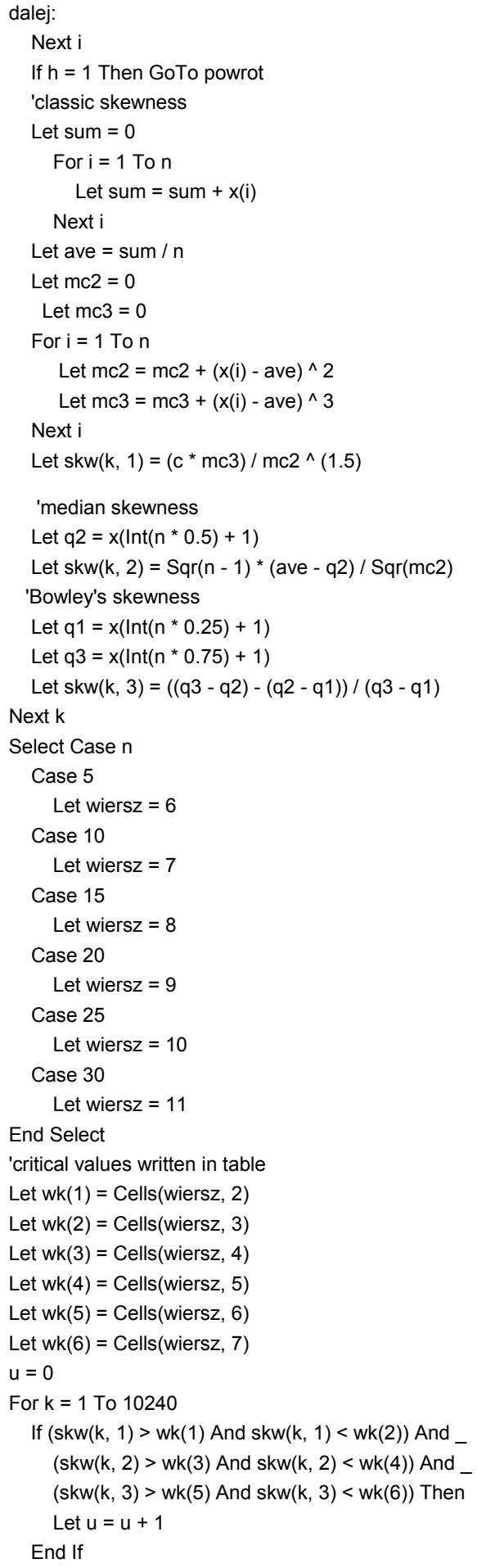

The classic skewness (3) was chosen as an argument of the PT function shown in Figures 2-4.

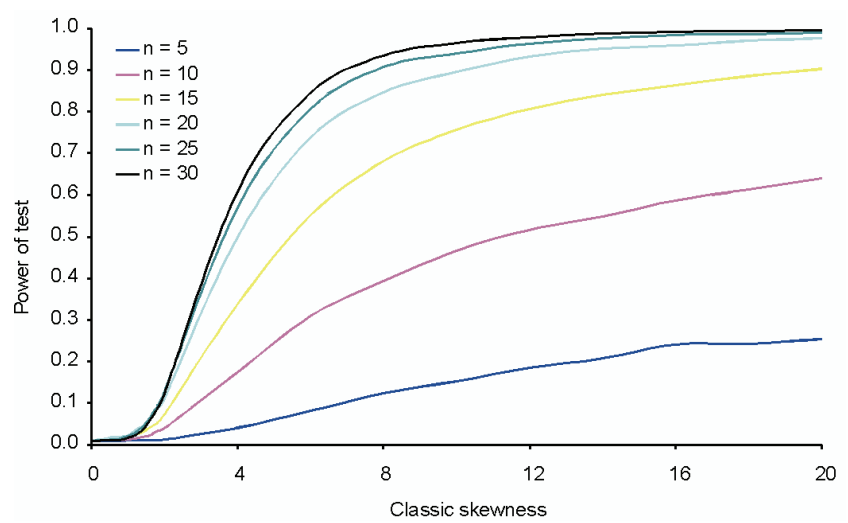

Fig. 2. Power of TFS test for a different sample size, at significance level $\alpha=0.01$

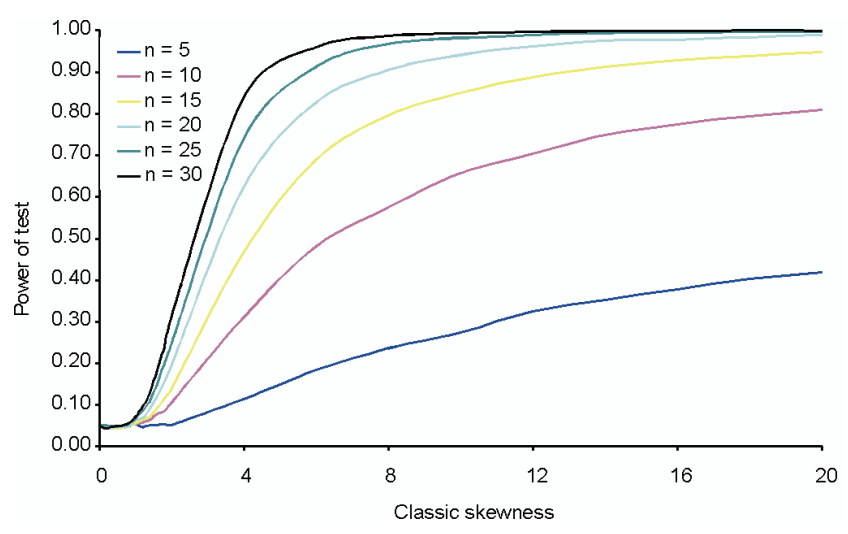

Fig. 3. Power of TFS test for a different sample size, at significance level $\alpha=0.05$

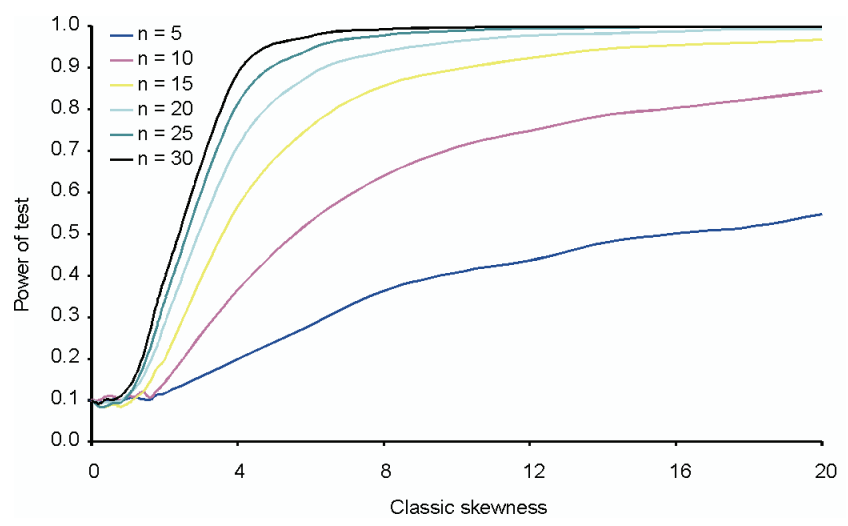

Fig. 4. Power of TFS test for a different sample size, at significance level $\alpha=0.1$

The TFS test was compared to the K-S test [8] for which an appropriate Monte Carlo study was carried out in parallel. This test is well-known and therefore only its results were shown. Better performance of the TFS test is readily seen (Figures 5-10). 


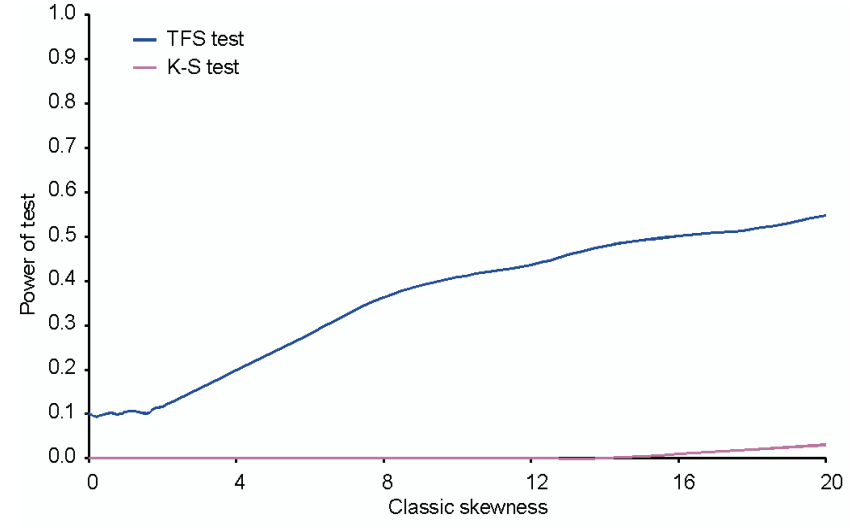

Fig. 5. Power of tests for a sample size $n=5$, at significance level $\alpha=0.1$

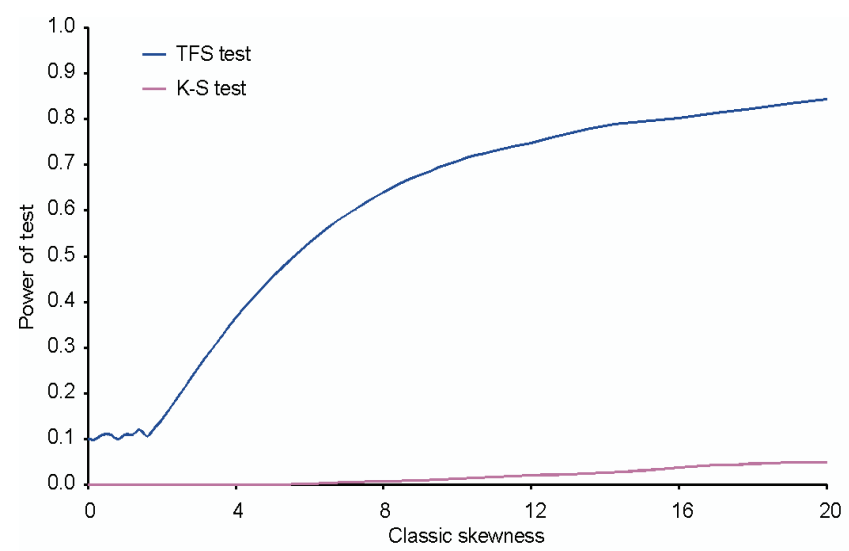

Fig. 6. Power of tests for a sample size $n=10$, at significance level $\alpha=0.1$

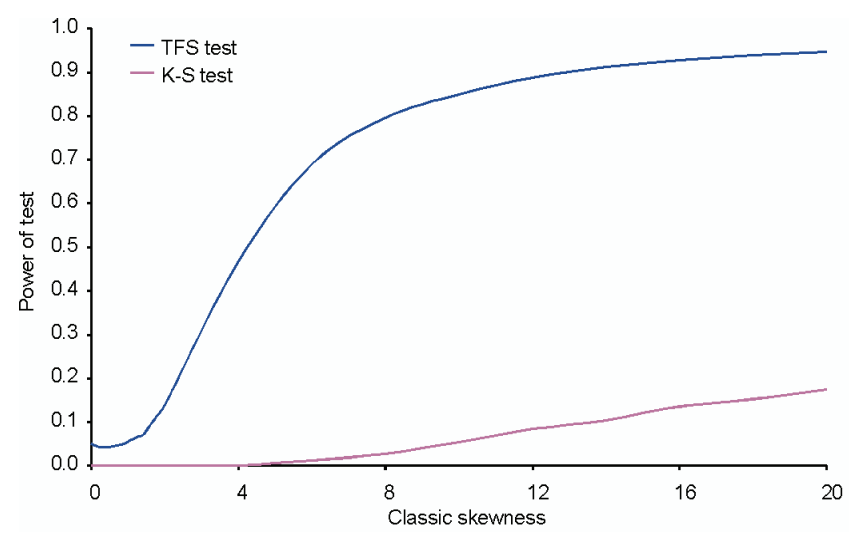

Fig. 7. Power of tests for a sample size $n=15$, at significance level $\alpha=0.05$

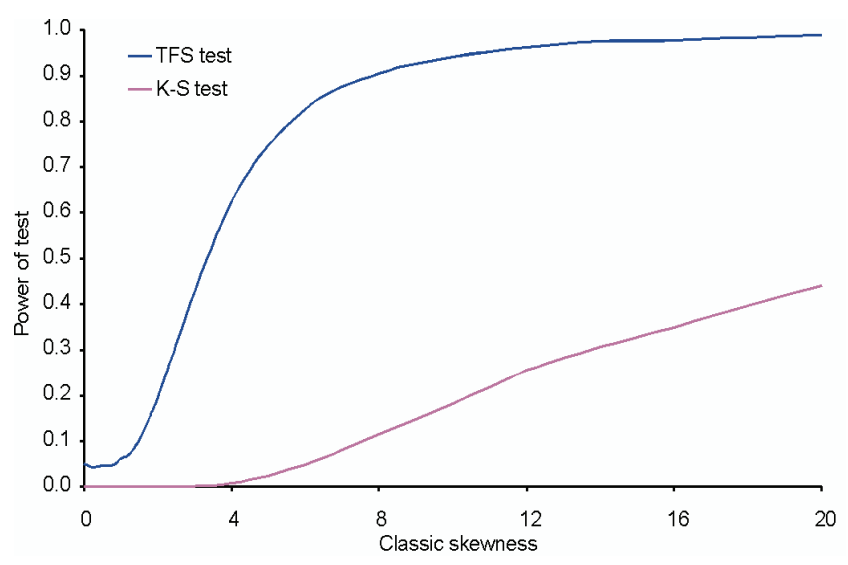

Fig. 8. Power of tests for a sample size $n=20$, at significance level $\alpha=0.05$

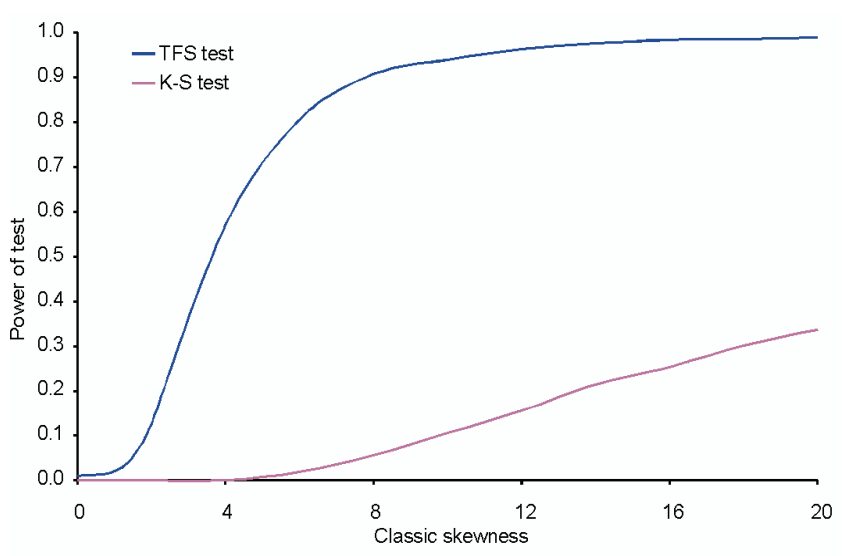

Fig. 9. Power of tests for a sample size $n=25$, at significance level $\alpha=0.01$

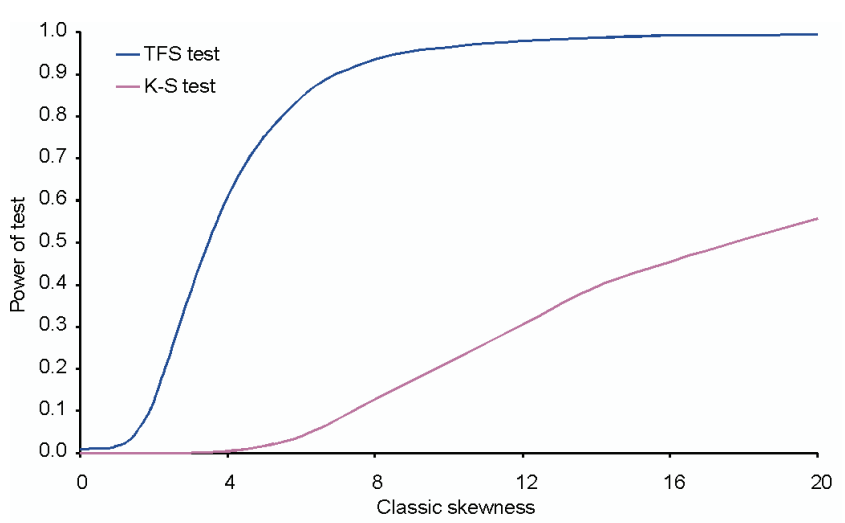

Fig. 10. Power of tests for a sample size $n=30$, at significance level $\alpha=0.01$ 


\section{References}

[1] H. Cramer, Mathematical methods in statistics, Warsaw 1958.

[2] H.A. David, Order statistics, Wiley, New York 1970.

[3] A. Drapella, Statistical inference on the base skewness and kurtosis, Pomeranian Pedagogical Academy, Słupsk 2004.

[4] J.F. Kenney, E.S. Keeping, Mathematics of statistics, Pt. 1, 3rd ed. Princeton, NJ: Van Nostrand 101-102 (1962).
[5] P. Sulewski, Testing for normality on the base skewness and kurtosis, Słupskie Prace Matematyczno - Fizyczne nr 3, 45-59 (2005).

[6] P. Sulewski, On differently defined skewness, Computational Methods in Science and Technology 14(1), 39-46 (2008).

[7] J. Walkenbach, Excel 2007 Power Programming with VBA, John Wiley \& Sons 2001

[8] W. Zieliński, Statistical tables, SGGW, Warsaw 2000.

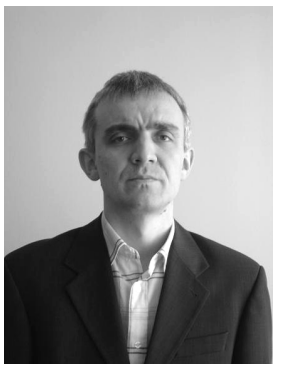

PIOTR SulewSKI graduated in Mathematics in 1996. Since then he has been working at the Institute of Mathematics at Pomeranian Academy in Stupsk. He received the $\mathrm{PhD}$ in reliability theory in 2001 from the Systems Research Institute of Polish Academy of Sciences in Warsaw. His research interests concern reliability mathematics and computational methods in statistics. 